\title{
Assessment of loaded squat jump height with a free-weight barbell and Smith machine: Comparison of the take-off velocity and...
}

Article in The Journal of Strength and Conditioning Research · July 2017

DOI: $10.1519 / J S C .0000000000002166$

CITATIONS

0

4 authors:

Alejandro Pérez Castilla

University of Granada

20 PUBLICATIONS 4 CITATIONS

SEE PROFILE

\section{Paul Comfort}

University of Salford

119 PUBLICATIONS 635 CITATIONS

SEE PROFILE
READS

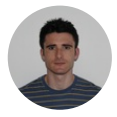

John J McMahon

University of Salford

45 PUBLICATIONS 121 CITATIONS

SEE PROFILE

\section{Amador García Ramos}

University of Granada

67 PUBLICATIONS 107 CITATIONS

SEE PROFILE

Some of the authors of this publication are also working on these related projects: 


\section{Assessment of loaded squat jump height with a free-weight barbell and Smith machine: comparison of the take-off velocity and flight time procedures}

Running head: Loaded squat jump height determination

Authors: Alejandro Pérez-Castilla, ${ }^{1}$ John J. McMahon, ${ }^{2}$ Paul Comfort, ${ }^{2}$ Amador García$\operatorname{Ramos}^{1}$

\section{Institutional Affiliations:}

${ }^{1}$ Department of Physical Education and Sport, Faculty of Sport Sciences, University of Granada, Granada, Spain.

${ }^{2}$ Directorate of Sport, Exercise and Physiotherapy, University of Salford, Salford, UK

\section{Corresponding author:}

Amador García-Ramos, Faculty of Sport Sciences, University of Granada, Ctra. Alfacar, s/n, 18011, Granada (Spain), Phone: (+34) 677815348, Fax: (+34) 958244369, E-mail: amagr@ugr.es

\section{ACKNOWLEDGMENTS}

We would like to thank all the students who selflessly participated in the study. This study was supported by the Spanish Ministry of Education, Culture and Sport under a pre-doctoral grant

(FPU15/03649) awarded to one of the authors (APC). 


\section{ABSTRACT}

The aims of this study were to compare the reliability and magnitude of jump height between the two standard procedures of analysing force platform data to estimate jump height (take-off velocity [TOV] and flight time [FT]) in the loaded squat jump (SJ) exercise performed with a free-weight barbell and in a Smith machine. Twenty-three collegiate men (age $23.1 \pm 3.2$ years, body mass $74.7 \pm 7.3 \mathrm{~kg}$, height $177.1 \pm 7.0 \mathrm{~cm}$ ) were tested twice for each SJ type (free-weight barbell and Smith machine) with 17, 30, 45, 60, and $75 \mathrm{~kg}$ loads. No substantial differences in reliability were observed between the TOV (Coefficient of variation $[\mathrm{CV}]$ : 9.88\%; Intraclass correlation coefficient [ICC]: 0.82) and FT (CV: 8.68\%; ICC: 0.88 ) procedures (CV ratio: 1.14), while the Smith SJ (CV: 7.74\%; ICC: 0.87) revealed a higher reliability than the free-weight $\mathrm{SJ}(\mathrm{CV}$ : 9.88\%; ICC: 0.81$)$ (CV ratio: 1.28$)$. The TOV procedure provided higher magnitudes of jump height than the FT procedure for the loaded Smith machine SJ (systematic bias: $2.64 \mathrm{~cm} ; P<0.05$ ), while no significant differences between the TOV and FT procedures were observed in the free-weight SJ exercise (systematic bias: $0.26 \mathrm{~cm} ; P>0.05$ ). Heteroscedasticity of the errors was observed for the Smith machine SJ $\left(r^{2}: 0.177\right)$ with increasing differences in favour of the TOV procedure for the trials with lower jump height (i.e. higher external loads). Based on these results the use of a Smith machine in conjunction with the FT more accurately determine jump height during the loaded SJ.

Key Words: force platform, reliability, vertical jump. 


\section{INTRODUCTION}

The vertical jump has received a lot of attention as a potential exercise for exploring lower-body muscle function $(8,17,22)$. The variable most commonly assessed is vertical jump height $(21,28)$. The use of vertical jump height as the main indicator of vertical jump performance could be justified by the strong correlations observed between vertical jump height and competitive performance in different sports (4,34-36). In this regard, vertical jump height is frequently assessed to evaluate the effectiveness of various training and rehabilitation interventions $(6,11,18)$.

The force platform is one of the measurement tools most commonly used to assess vertical jump height (20). Two standard procedures can be used to estimate vertical jump height from the force platform data: the take-off velocity (TOV) and the flight time (FT). The TOV procedure has been suggested to be the most accurate to determine vertical jump height (20,25). However, the precise estimation of vertical jump height from the TOV requires an accurate determination of the body or system mass from the force-time recording commonly taken during the quiet standing period that precedes the initiation of the jump. On the other hand, the precision of the FT procedure is compromised when the subjects do not land with their lower limbs fully extended (1,25). Although both the TOV and FT procedures have been extensively used, there is a shortage of knowledge regarding which of the two procedures is able to determine jump height with higher reliability, particularly during loaded vertical jumps. 
The squat jump (SJ) is an exercise commonly used for training and testing the lowerbody muscles since the ability to quickly accelerate the body from a resting position is important in many sports (30). Similarly, the SJ is also used to evaluate the ability of the subjects to exert force against different external loads $(12,18)$. The loaded SJ has been typically performed with both a free-weight barbell (the barbell is free to move in any direction) and with a Smith machine (the displacement of the barbell is restricted to a vertical direction) $(19,27,32)$. However, the reliability of jump height performance between both SJ types has not been explored yet. It is also unknown whether differences exist in the magnitude of jump height performance between the TOV and FT procedures in the loaded SJ exercise, as well as whether these possible differences could be dependent of the loaded SJ type evaluated (free-weight barbell vs. Smith machine) or the applied external load.

To address the existing gaps in the literature, the specific aims of the present study were 1) to determine the between-session reliability of jump height performance calculated from TOV and FT procedures in the loaded SJ performed with a free-weight barbell and with a Smith machine, and 2) to compare the jump height performance between the TOV and FT procedures for each SJ type. We hypothesized that 1) the TOV procedure would provide a higher reliability than the FT procedure due to a minor influence of the execution technique (25), as well as the use of a Smith machine would provide jump height performance with higher reliability due to the reduction in the kinematic redundancy, and 2) while similar jump height performance would be obtained by the TOV and FT procedures with the free-weight barbell loaded SJ exercise, the TOV procedure would overestimate the jump height compared to the FT procedure in the Smith machine loaded SJ exercise due to effect of the friction force with the two linear bearings of the Smith machine vertical bars. 


\section{METHODS}

Experimental approach to the problem

A repeated-measures design was used to compare the reliability and magnitude of jump height performance between the two standard procedures of analysing force platform data to estimate jump height: TOV and FT. Following two familiarisation sessions, subjects undertook four testing sessions (twice per week) over two weeks with 48-72 $\mathrm{h}$ of rest between them. In a counterbalanced order, they performed two sessions of the loaded SJ exercise with a free-weight barbell over one week and two sessions of the loaded SJ exercise with a Smith machine in another week. All sessions were conducted in the laboratory under the direct supervision of a skilled investigator, at the same time of day for each subject $( \pm 1$ h), and under similar environmental conditions $\left(\sim 22^{\circ} \mathrm{C}\right.$ and $\sim 60 \%$ humidity).

\section{Subjects}

Twenty-three collegiate men (age $23.1 \pm 3.2$ years, body mass $74.7 \pm 7.3 \mathrm{~kg}$, height $177.1 \pm 7.0 \mathrm{~cm}$ ) volunteered to take part in this study. All subjects were physically active sports science students with a minimum of two years of resistance training experience. Subjects were instructed to avoid any strenuous exercise over the course of the present study. None of them reported physical limitations, health problems or musculoskeletal injuries that could compromise tested performance. All subjects were informed of the benefits and risks of the investigations prior to signing an informed consent form in accordance with the Institutional Review Board and The Code of Ethics of the World Medical Association (Declaration of Helsinki). 


\section{Testing procedures}

Subjects arrived at the laboratory in a well-rested condition at the start of each testing session. Prior to the commencement of testing, they performed a 10 min standardized warmup that included light jogging, joint mobility, dynamic stretching, six unloaded SJ, and three loaded SJ with $17 \mathrm{~kg}$ (mass of the unloaded Smith machine barbell) in the assessed exercise. Thereafter, either the free-weight barbell or Smith machine loaded SJ exercises against external loads of 17, 30, 45, 60 and $75 \mathrm{~kg}$ were performed. The maximum tested load was 75 $\mathrm{kg}$ because all subjects were able to jump with correct technique with this load or more during familiarisation sessions. The external loads were applied in a randomized order, but the same sequence of individual loads was maintained for each subject through all testing sessions. Two repetitions were recorded at each load. Rest periods of 3-4 min between the trials of both the same and different loads were implemented.

The loaded SJ technique involved the subjects standing with the knees and hips fully extended, feet approximately shoulder-width apart, and the barbell held across the top of the shoulders and upper back. Thereafter, they descended in a continuous motion until reaching $90^{\circ}$ of knee flexion (24). Subjects were instructed to hold the static position at $90^{\circ}$ knee flexion for $1.5 \mathrm{~s}$, and afterwards they performed the concentric action with the instruction of maximizing vertical jump height (9). Countermovement was verbally restricted and carefully checked after each trial through the examination of the force-time curve. Subjects were also instructed to land with the hips and knees extended and the ankle joints in plantar flexion. If these criteria were not met, the trial was repeated. Trained spotters were present to verbally encourage the subjects throughout the test and lifting belts were used to ensure safety. Two loaded SJ types were performed: (1) free-weight barbell SJ in which the load was free to move in any direction without imposing any restriction to the movement (29), and 2) Smith 
machine SJ in which the movement of the barbell was restricted to the vertical direction by the two linear bearings of the Smith machine (14).

\section{Data analysis}

Vertical jumps were performed on a force platform (Dinascan/IBV, Biomechanics Institute of Valencia, Spain) that sampled the vertical ground reaction force data at a frequency of $1,000 \mathrm{~Hz}$ (33). Two standard procedures were used to calculate jump height from the force platform data:

- Take-off velocity (TOV): Prior to each jump, subjects were weighed over $4 \mathrm{~s}$ with the external load over their shoulders to determine the total system weight (sum of body weight and external weight). The initiation of the concentric phase was identified as the first time instant when the vertical ground reaction force was $10 \mathrm{~N}$ above the total system weight, while take-off was defined as the time instant when the ground reaction force was below $5 \mathrm{~N}$ (9). The net force was calculated as the amount of force exceeding the system weight. The net impulse of the concentric phase was calculated through the trapezoidal rule, and then divided by the system mass to determine the TOV. Finally, jump height was calculated from the TOV by the following equation, where $g$ represent the acceleration of gravity $\left(9.81 \mathrm{~m} \cdot \mathrm{s}^{-2}\right)$ :

$$
\text { Iumpheight }=\frac{\text { TOV }^{3}}{2 \times g}
$$

- Flight time (FT): The FT was defined as the time period between take-off and landing. The contact after flight was identified as the instant when the vertical ground reaction force exceeded $10 \mathrm{~N}$. Jump height was obtained from the FT using the following equation, where $g$ represent the acceleration of gravity $\left(9.81 \mathrm{~m} \cdot \mathrm{s}^{-2}\right)$ : 


$$
\text { Jumpheight }=\frac{g \times F T^{2}}{\mathbf{8}}
$$

The data of both sessions for each SJ type was used to address the first objective (between-session reliability), while only the data of the second session of each SJ type was used to address the second objective (magnitude comparisons). Only the trial with the highest jump height performance at each load was selected for further analysis. Specifically, the best trial of each procedure (TOV and FT) was selected for the between-session reliability analysis, while the trial with the highest jump height according to the FT procedure was used for magnitude comparisons.

\section{Statistical analyses}

Data are presented as means and standard deviations, while the coefficient of variation $(\mathrm{CV})$ are presented through their median values and ranges. Paired samples $t$-tests and standardized mean difference (Cohen's d effect size, ES) were used to compare the magnitudes of the jump height between both testing sessions. The criteria to interpret the magnitude of the ES was as follows: trivial $(<0.2)$, small (0.2-0.59), moderate (0.60-1.19), large (1.2-2.0) or very large (> 2.0) (16). Between-session reliability was assessed by the standard error of measurement (SEM), the $\mathrm{CV}$, and the intraclass correlation coefficient (ICC) with their corresponding 95\% confidence interval. Acceptable reliability was determined as an ICC $>0.70$ and a CV $<10 \%(10)$. Paired samples $t$-tests were used to compare the CVs between procedures (TOV vs. FT) and jump types (free-weight barbell vs. Smith machine). To interpret the magnitude of differences observed between two CVs, a criterion for the smallest important ratio was established as higher than 1.15 (9). A three-way repeated measures analysis of variance (ANOVA) (procedure [TOV vs. FT], jump type [free- 
weight barbell vs. Smith machine], and load [17, 30, 45, 60, $75 \mathrm{~kg}]$ with Bonferroni post-hoc test was applied to compare the magnitudes of jump height performance. Eta squared $\left(\eta^{2}\right)$ was calculated for the ANOVA where the values of the effect sizes $0.01,0.06$ and above 0.14 were considered small, medium, and large, respectively (7). Bland-Altman plots were also constructed to examine the presence of systematic and proportional bias between the TOV and FT procedures separately for each SJ type. Heteroscedasticity of error was defined as an $r^{2}>0.1$ (3). Statistical significance was accepted at $P<0.05$ level. All reliability assessments were performed by means of a custom spreadsheet (15), while other statistical analyses were performed using the software package SPSS (IBM SPSS version 22.0, Chicago, IL, USA).

\section{RESULTS}

No significant and generally trivial differences were observed for vertical jump height performance between both testing sessions irrespective of the calculation method used (Table 1). Jump height reached acceptable reliability for all loading conditions with the exception of the heavy external loads (60 and $75 \mathrm{~kg}$ ). No substantial differences in reliability were observed between the TOV $(\mathrm{CV}=9.88 \%[6.22 \%-17.73 \%])$ and FT procedures $(\mathrm{CV}=8.68 \%$ $[4.58 \%-19.46 \%])(P=0.099 ; \mathrm{CV}$ ratio $=1.14)$, while the Smith SJ $(\mathrm{CV}=7.74 \%[4.58 \%$ $17.73 \%])$ revealed a higher reliability than the free-weight $\mathrm{SJ}(\mathrm{CV}=9.88 \%[7.54 \%-19.46 \%])$ $(P=0.009 ; \mathrm{CV}$ ratio $=1.28)$. In general, the Smith machine in conjunction with the FT procedure was the most reliable combination for testing SJ height performance.

\section{--- Table 1 near here ---}


The three-way repeated measures ANOVA revealed significant main effect of the procedure $\left(\mathrm{F}=63.633, P<0.001, \eta_{p}^{2}=0.743\right)$, jump type $\left(\mathrm{F}=5.797, P=0.025, \eta_{p}^{2}=0.209\right)$ and load $\left(\mathrm{F}=693.752, P<0.001, \eta_{p}^{2}=0.969\right)$. The two-way interactions of the procedure $\times$ jump type $\left(\mathrm{F}=105.216, P<0.001, \eta_{p}^{2}=0.827\right)$, procedure $\times \operatorname{load}(\mathrm{F}=15.042 .752, P<$ $\left.0.001, \eta_{p}^{2}=0.406\right)$ and the three-way interactions $\left(\mathrm{F}=9.061, P<0.001, \eta_{p}^{2}=0.292\right)$ were also significant, but not the two-way interaction jump type $\times$ load $(\mathrm{F}=2.033, P=0.119), \eta_{p}^{2}$ $=0.085)$. The main effects revealed that the magnitudes of jump height were (1) higher for the TOV than the FT procedure, (2) higher for the Smith SJ than free-weight SJ, and (3) decrease with the increment of the load. The most prominent interaction revealed that the higher magnitude of jump height obtained from the TOV procedure was obtained in the SJ performed in a Smith machine, especially for the heavy external loads (60 and $75 \mathrm{~kg}$ ) (Figure 1).

\section{--- Figure 1 near here ---}

Bland-Altman plots revealed systematic bias in favour of the TOV procedure for the SJ performed in the Smith machine, while no systematic bias between the TOV and FT procedures was observed for the free-weight SJ (Figure 2). Heteroscedasticity of the errors was observed for the SJ performed in the Smith machine $\left(r^{2}=0.177\right)$ with increasing differences in favour of the TOV procedure for the trials with lower jump height (i.e. higher external loads). No heteroscedasticity of the errors was observed for the free-weight SJ $\left(r^{2}=\right.$ $0.005)$. 


\section{DISCUSSION}

The present study was designed to compare the reliability and magnitude of jump height performance between the two standard procedures of analysing force platform data to estimate jump height (TOV and FT) in the loaded SJ exercise performed with a free-weight barbell and in a Smith machine. Our first hypothesis was partially rejected. Namely, while no meaningful differences in reliability were observed between the TOV and FT procedures $(\mathrm{CV}$ ratio $<1.15)$, the Smith machine provided jump height performance with higher reliability than the free-weight barbell $(\mathrm{CV}$ ratio $>1.15)$. Our second hypothesis was confirmed since the TOV procedure provided higher magnitudes of jump height than the FT procedure for the loaded SJ performed in a Smith machine. No significant differences between the TOV and FT procedures were observed in the free-weight loaded SJ exercise. Taking these results together, it is recommended the use of a Smith machine in conjunction with the FT procedure to accurately determine loaded SJ height performance.

The TOV and FT procedures assessed in the present study have been routinely used to estimate jump height performance from the vertical ground reaction force data recorded by a force platform $(5,13,23)$. Of interest to coaches and strength and conditioning professionals would be the identification of which of the two standard procedures allow them to detect jump height performance changes with higher precision. Due to the influence of jump technique, especially during the landing, we hypothesized that the TOV procedure would provide jump height with higher reliability than the FT procedure. This hypothesis was rejected since the $\mathrm{CV}$ ratio comparing the absolute reliability (i.e. $\mathrm{CV}$ values) between both procedures did not exceed the smallest important ratio of 1.15. Moir et al. (26) reported slightly higher reliability for the TOV procedure ( $\mathrm{CV}=2.1 \%$ in men and $2.2 \%$ in women) 
than the FT procedure $(\mathrm{CV}=2.3 \%$ in men and $2.6 \%$ in women $)(\mathrm{CV}$ ratio $=1.10$ for men and 1.18 for women) during the unloaded countermovement jump (CMJ) exercise. Contrary to Moir et al. (26), our results suggest that the FT procedure could be slightly more reliable than the TOV procedure in the loaded $\mathrm{SJ}(\mathrm{CV}$ ratio $=1.14)$. This apparent contradictory result may be explained because the exact initiation of the jump, which should be accurately determined to precisely estimate jump height from the TOV procedure, is more difficult to determine in the SJ (subjects start the jump holding a $90^{\circ}$ squat position isometrically) than in the CMJ (subjects initiate the jump from an extended position). This problem could be further accentuated in the loaded SJ since the subjects have to hold the $90^{\circ}$ squat position with an external load on their shoulders.

Since the loaded SJ have been indistinctly assessed with a free-weight barbell or with a Smith machine, we attempted to clarify whether one of the two SJ types is more reliable than the other. Our hypothesis was confirmed since the Smith machine, which allows only a vertical displacement of the barbell along a fixed pathway, provided loaded SJ height performance with higher reliability than the free-weight barbell. The increased reliability observed with the use of a Smith machine could be explained by the reduction in the kinematic redundancy that might allow a more reproducible technique. It is worth noting that the greater differences in reliability were observed at heavier loads. It is plausible that the constraint of having to balance the heavy loads prior to the initiation of the jump (i.e., at $90^{\circ}$ knee flexion) is minimized in the Smith machine compared to the free-weight exercise. However, it should be noted that the use of a Smith machine presents some potential limitations (e.g. high cost, low versatility, lower ecological validity, etc.) that limit its use to laboratory conditions. It is also plausible that more skilled subjects (i.e. high level athletes) would have presented lower differences in reliability between the Smith machine and the free-weight barbell loaded SJ (2). Although further studies are needed to clarify this 
assumptions, when testing loaded SJ height in recreational subjects the use of a Smith machine could be recommended.

We also examined the differences in the magnitude of jump height performance between the TOV and FT procedures separately for each SJ type. Our second hypothesis was confirmed since the jump height did not differ between the TOV and FT procedures in the free-weight barbell loaded SJ exercise, while the TOV procedure overestimated the jump height compared to the FT procedure in the Smith machine loaded SJ exercise. The effect of the friction force with the two linear bearings of the Smith machine vertical bars could have caused an overestimation of the TOV, and consequently of the jump height performance (14). It is plausible that the frictional forces resulted in a greater time of propulsion, thereby inflating the net vertical impulse and therefore the TOV. The overestimation of jump height performance by the TOV procedure was accentuated under higher external loads, which can be consequence of a longer jump execution time. Therefore, sport practitioners should we aware that the true jump height performance may be overestimated in the Smith machine when the TOV procedure is used. The magnitude of the overestimation could be directly related to the friction force imposed by the two linear bearings of the Smith machine.

A simple field method, which uses jump height as input variable (together with the push-off distance and system mass), has been recently proposed to assess the mechanical capacities of lower-body muscles through loaded vertical jumps (30). Individual forcevelocity profiles can be determined through the application of multiple maximum loaded vertical jumps (usually 4 to 6 external loads) that provide a wide range of force and velocity data. It has been proposed that each individual presents an optimal force-velocity profile that maximizes ballistic performance (31). In this regard, a training program individually targeted 
to reduce an athlete's deficit in force or velocity capacities has proven to be effective to enhance ballistic performance (18). As demonstrated by Jiménez-Reyes et al. (18), our results suggest that the most reliable combination to obtain the force-velocity relationship could be through the jump height obtained from the FT procedure in a Smith machine. Of apparent importance here is the increased overestimation of the jump height by the TOV procedure together with the progressive increment in the load (see Figure 2). This implies that the modelling of the force-velocity relationship through the impulse-momentum approach in vertical jumps performed in a Smith machine might provide different force-velocity profiles (more oriented towards force capacity) than the one that could be obtained from Samozino's equations using the FT procedure $(30,31)$.

\section{PRACTICAL APPLICATIONS}

The use of a Smith machine in conjunction with the FT procedure seems to be the preferred approach to accurately determine loaded SJ height performance. It should be noted that vertical jump height performance was overestimated when using the TOV procedure in the Smith machine loaded SJ exercise, while no differences between both the TOV and FT procedures were observed in the free-weight loaded SJ. Further studies should investigate whether similar findings are obtained in other vertical jump types (e.g. CMJ) as well as in more skilled populations such as high level athletes that are more familiarized with the loaded vertical jump exercise. The greater reliability obtained for the FT procedure support the use of more practical and affordable measurement methods (e.g. contact mat, smartphone app, etc.) that allow to estimate jump height from the FT procedure. 


\section{REFERENCES}

1. Aragón-Vargas, LF. Evaluation of four vertical jump tests: Methodology, reliability, validity, and accuracy. Meas Phys Educ Exerc Sci 4: 215-228, 2000.

2. Aragón-Vargas, LF and Gross, MM. Kinesiological factors in vertical jump performance: Differences among individuals. J Appl Biomech 13: 24-44, 1997.

3. Atkinson, G and Nevill, AM. Statistical methods for assessing measurement error (reliability) in variables relevant to sports medicine. Sports Med 26: 217-238, 1998.

4. Barnes, JL, Schilling, BK, Falvo, MJ, Weiss, LW, Creasy, AK, and Fry, AC. Relationship of jumping and agility performance in female volleyball athletes. $J$ Strength Cond Res 21: 1192-6, 2007.

5. Chamari, K, Hachana, Y, Ahmed, YB, Galy, O, Sghaier, F, Chatard, JC, Hue O and Wisløff, U. Field and laboratory testing in young elite soccer players. Br J Sports Med 38: 191-196, 2004.

6. Chelly, MS, Ghenem, MA, Abid, K, Hermassi, S, Tabka, Z, and Shephard, RJ. Effects of in-season short-term plyometric training program on leg power, jump- and sprint performance of soccer players. J Strength Cond Res 24: 2670-2676, 2010.

7. Cohen, J. Statistical power analysis for the behavioral sciences. $2^{\text {nd }}$ ed. Hillsdale, MI: Lawrence Erlbaum Associates, 1988.

8. Dowling, JJ and Vamos, L. Identification of kinetic and temporal factors related to vertical jump performance. J Appl Biomech 9: 95-110, 1993.

9. Garcia-Ramos, A, Feriche, B, Perez-Castilla, A, Padial, P, and Jaric, S. Assessment of leg muscles mechanical capacities: Which jump, loading, and variable type provide the most reliable outcomes? Eur J Sport Sci, 6: 690-698, 2017.

10. García-Ramos, A, Jaric, S, Pérez-Castilla, A, Padial, P, and Feriche, B. Reliability and magnitude of mechanical variables assessed from unconstrained and constrained 
loaded countermovement jumps. Sport Biomech 1-13, 2017. Epub ahead of print.

11. García-Ramos, A, Padial, P, De la Fuente, B, Argüelles-Cienfuegos, J, BonitchGóngora, J, and Feriche, B. Relationship between vertical jump height and swimming start performance before and after an altitude training camp. J Strength Cond Res 30: $1638-1645,2016$.

12. García-Ramos, A, Štirn, I, Padial, P, Argüelles-Cienfuegos, J, De la Fuente, B, Calderón, C, Bonitch-Góngora, J, Tomazin, K, Strumbelj, B, Strojnik, V, and Feriche, B. The effect of an altitude training camp on swimming start time and loaded squat jump performance. PLoS One 11: e0160401, 2016.

13. García-Ramos, A, Stirn, I, Padial, P, Argüelles-Cienfuegos, J, De la Fuente, B, Strojnik, V, and Feriche, B. Predicting vertical jump height from bar velocity. $J$ Sports Sci Med 14: 256-262, 2015.

14. García-Ramos, A, Štirn, I, Strojnik, V, Padial, P, De la Fuente, B, ArgüellesCienfuegos, J, and Feriche, B. Comparison of the force-, velocity-, and power-time curves recorded with a force plate and a linear velocity transducer. Sports Biomech 15: 329-341, 2016.

15. Hopkins, W. Calculations for reliability (Excel spreedsheet). A new view statistics, 2000. Available from: http://www.sportsci.org/resource/stats/relycalc.html\#excel.

16. Hopkins, WG, Marshall, SW, Batterham, AM, and Hanin, J. Progressive statistics for studies in sports medicine and exercise science. Med Sci Sports Exerc 41: 3-13, 2009.

17. Jiménez-Reyes, P, Pareja-Blanco, F, Rodríguez-Rosell, D, Marques, MC, and González-Badillo, JJ. Maximal velocity as a discriminating factor in the performance of loaded squat jumps. Int J Sports Physiol Perform 11: 227-234, 2016.

18. Jiménez-Reyes, P, Samozino, P, Brughelli, M, and Morin, J-B. Effectiveness of an 
individualized training based on force-velocity profiling during jumping. Front Physiol 7: 677, 2017.

19. Jimenez-Reyes, P, Samozino, P, Pareja-Blanco, F, Conceicao, F, Cuadrado-Penafiel, V, Gonzalez-Badillo, JJ, and Morin JB. Validity of a simple method for measuring force-velocity-power profile in countermovement jump. Int J Sports Physiol Perform 12: $36-43,2017$.

20. Linthorne, NP. Analysis of standing vertical jumps using a force platform. Am J Phys 69: 1198-1204, 2001.

21. Markovic, G. Does plyometric training improve vertical jump height? A metaanalytical review. Br J Sports Med 41: 349-355, 2007.

22. Markovic, G, Dizdar, D, Jukic, I, and Cardinale, M. Reliability and factorial validity of squat and countermovement jump tests. J strength Cond Res 18: 551-555, 2004.

23. McMahon, JJ, Jones, PA, and Comfort, P. A correction equation for jump height measured using the just jump system. Int J Sports Physiol Perform 11: 555-557, 2016.

24. Mitchell, LJ, Argus, CK, Taylor, K-L, Sheppard, JM, and Chapman, DW. The effect of initial knee angle on concentric-only squat jump performance. Res $Q$ Exerc Sport 2: 184-192, 2017.

25. Moir, GL. Three different methods of calculating vertical jump height from force platform data in men and women. Meas Phys Educ Exerc Sci 12: 207-218, 2008.

26. Moir, GL, Garcia, A, and Dwyer, GB. Intersession reliability of kinematic and kinetic variables during vertical jumps in men and women. Int J Sports Physiol Perform 4: $317-330,2009$

27. Newton, RU, Kraemer, WJ, and Häkkinen, K. Effects of ballistic training on preseason preparation of elite volleyball players. Med Sci Sports Exerc 31: 323-330, 1999.

28. Saéz-Saez de Villarreal, E, Kellis, E, Kraemer, WJ, and Izquierdo, M. Determining 
variables of plyometric training for improving vertical jump height performance: a meta-analysis. J Strength Cond Res 23: 495-506, 2009.

29. Samozino, P, Edouard, P, Sangnier, S, Brughelli, M, Gimenez, P, and Morin, JB. Force-velocity profile: Imbalance determination and effect on lower limb ballistic performance. Int J Sports Med 35: 505-510, 2014.

30. Samozino, P, Morin, JB, Hintzy, F, and Belli, A. A simple method for measuring force, velocity and power output during squat jump. J Biomech 41: 2940-2945, 2008.

31. Samozino, P, Rejc, E, Di Prampero, PE, Belli, A, and Morin, JB. Optimal forcevelocity profile in ballistic movements-Altius: Citius or Fortius? Med Sci Sports Exerc 44: 313-322, 2012.

32. Stone, MH, O’Bryant, HS, McCoy, L, Coglianese, R, Lehmkuhl, M, and Schilling, B. Power and maximum strength relationships during performance of dynamic and static weighted jumps. J Strength Cond Res 17: 140-147, 2003.

33. Street, G, McMillan, S, Board, W, Rasmussen, M, and Heneghan, JM. Sources of error in determining countermovement jump height with the impulse method. J Appl Biomech 17: 43-54, 2001.

34. Vandewalle, H, Peres, G, Heller, J, Panel, J, and Monod, H. Force-velocity relationship and maximal power on a cycle ergometer. Correlation with the height of a vertical jump. Eur J Appl Physiol Occup Physiol 56: 650-656, 1987.

35. Vescovi, JD and Mcguigan, MR. Relationships between sprinting, agility, and jump ability in female athletes. J Sports Sci 26: 97-107, 2008.

36. West, DJ, Owen, NJ, Cunningham, DJ, Cook, CJ, and Kilduff, LP. Strength and power predictors of swimming starts in international sprint swimmers. J Strength Cond Res 25: 950-955, 2011. 


\section{FIGURE LEGENDS}

Figure 1. Comparison of the jump height performance observed from the take-off velocity (TOV and flight time (FT) procedures between the free-weight and Smith loaded SJ. Percent

differences $(\%)=$

Significant differences between jump types are determined through paired samples t-test.

Figure 2. Bland-Altman plots showing differences between the jump height performance calculated from the take-off velocity procedure (TOV) and flight time (FT) procedures. Each plot depicts the averaged difference and 95\% limits of agreement (dashed lines), along with the regression line (solid line) $(\mathrm{n}=115)$. 
Table 1. Reliability of the jump height calculated from the take-off velocity (TOV) and flight time (FT) procedures in the loaded squat jump exercise.

\begin{tabular}{|c|c|c|c|c|c|c|c|c|c|}
\hline Procedure & Jump type & Load (kg) & Session $1(\mathrm{~cm})$ & Session $2(\mathrm{~cm})$ & $P$ & $\mathrm{ES}$ & $\mathrm{CV}(95 \% \mathrm{CI})$ & ICC $(95 \% \mathrm{CI})$ & $\operatorname{SEM}(95 \% \mathrm{CI})(\mathrm{cm})$ \\
\hline \multirow{10}{*}{ TOV } & \multirow{5}{*}{$\begin{array}{c}\text { Free- } \\
\text { weight }\end{array}$} & 17 & $22.6 \pm 5.0$ & $21.9 \pm 3.9$ & 0.28 & -0.16 & $10.04(7.76,14.21)$ & $0.77(0.53,0.89)$ & $2.23(1.73,3.16)$ \\
\hline & & 30 & $17.8 \pm 4.3$ & $18.0 \pm 3.4$ & 0.71 & 0.05 & $9.72(7.52,13.75)$ & $0.81(0.60,0.91)$ & $1.74(1.35,2.47)$ \\
\hline & & 45 & $13.6 \pm 3.5$ & $13.9 \pm 3.2$ & 0.49 & 0.07 & $8.09(6.26,11.45)$ & $0.90(0.78,0.96)$ & $1.11(0.86,1.57)$ \\
\hline & & 60 & $9.0 \pm 2.8$ & $9.5 \pm 3.3$ & 0.23 & 0.16 & $14.61(11.30,20.67)$ & $0.82(0.62,0.92)$ & $1.35(1.05,1.91)$ \\
\hline & & 75 & $7.4 \pm 2.7$ & $8.1 \pm 2.9$ & 0.06 & 0.27 & $17.18(13.29,24.32)$ & $0.80(0.58,0.91)$ & $1.33(1.03,1.88)$ \\
\hline & \multirow{5}{*}{ Smith } & 17 & $22.5 \pm 3.4$ & $22.7 \pm 3.8$ & 0.59 & 0.06 & $6.22(4.81,8.80)^{\mathrm{a}, \mathrm{c}}$ & $0.86(0.70,0.94)$ & $1.41(1.09,1.99)$ \\
\hline & & 30 & $19.2 \pm 3.4$ & $19.6 \pm 3.3$ & 0.32 & 0.11 & $6.54(5.05,9.25)^{\mathrm{a}, \mathrm{c}}$ & $0.87(0.72,0.94)$ & $1.27(0.98,1.79)$ \\
\hline & & 45 & $16.1 \pm 3.3$ & $16.2 \pm 3.6$ & 0.87 & 0.02 & $7.91(6.12,11.19)$ & $0.87(0.72,0.94)$ & $1.28(0.99,1.81)$ \\
\hline & & 60 & $11.9 \pm 3.0$ & $12.4 \pm 3.2$ & 0.38 & 0.16 & $14.93(11.55,21.13)$ & $0.67(0.37,0.85)$ & $1.82(1.40,2.57)$ \\
\hline & & 75 & $10.7 \pm 3.7$ & $10.7 \pm 3.1$ & 0.94 & 0.01 & $17.73(13.71,25.09)$ & $0.71(0.43,0.87)$ & $1.89(1.46,2.68)$ \\
\hline \multirow{10}{*}{ FT } & \multirow{5}{*}{$\begin{array}{l}\text { Free- } \\
\text { weight }\end{array}$} & 17 & $21.3 \pm 3.8$ & $21.8 \pm 3.7$ & 040 & 0.13 & $8.79(6.80,12.45)$ & $0.76(0.52,0.89)$ & $1.90(1.47,2.69)$ \\
\hline & & 30 & $17.3 \pm 3.2$ & $17.4 \pm 3.5$ & 0.71 & 0.05 & $8.57(6.62,12.45)$ & $0.82(0.62,0.92)$ & $1.49(1.15,2.10)$ \\
\hline & & 45 & $13.0 \pm 3.2$ & $13.4 \pm 2.5$ & 0.25 & 0.12 & $7.54(5.84,10.68)$ & $0.89(0.76,0.95)$ & $0.99(0.77,1.41)$ \\
\hline & & 60 & $8.6 \pm 2.8$ & $9.0 \pm 2.6$ & 0.32 & 0.15 & $15.08(11.66,21.35)$ & $0.78(0.54,0.90)$ & $1.33(1.02,1.88)$ \\
\hline & & 75 & $6.6 \pm 2.6$ & $7.2 \pm 2.6$ & 0.12 & 0.25 & $19.46(15.05,27.55)$ & $0.74(0.48,0.88)$ & $1.35(1.04,1.91)$ \\
\hline & \multirow{5}{*}{ Smith } & 17 & $21.5 \pm 3.3$ & $21.4 \pm 3.8$ & 0.67 & -0.03 & $4.58(3.54,6.48)^{\mathrm{a}, \mathrm{b}, \mathrm{c}}$ & $0.93(0.84,0.97)^{\mathrm{a}, \mathrm{c}}$ & $0.98(0.76,1.39)$ \\
\hline & & 30 & $17.1 \pm 3.2$ & $17.3 \pm 3.2$ & 0.47 & 0.07 & $5.60(4.33,7.93)^{\mathrm{a}, \mathrm{b}, \mathrm{c}}$ & $0.92(0.81,0.96)^{\mathrm{a}}$ & $0.96(0.74,1.36)$ \\
\hline & & 45 & $12.8 \pm 3.0$ & $13.0 \pm 3.2$ & 0.52 & 0.06 & $7.57(5.86,10.72)$ & $0.91(0.80,0.96)$ & $0.98(0.76,1.38)$ \\
\hline & & 60 & $8.1 \pm 2.7$ & $8.6 \pm 2.8$ & 0.07 & 0.19 & $10.98(8.49,15.54)^{\mathrm{a}, \mathrm{b}, \mathrm{c}}$ & $0.90(0.78,0.96)^{b, c}$ & $0.91(0.71,1.29)$ \\
\hline & & 75 & $6.3 \pm 2.3$ & $6.6 \pm 2.6$ & 0.31 & 0.16 & $14.84(11.48,21.00)^{\mathrm{a}, \mathrm{b}, \mathrm{c}}$ & $0.86(0.69,0.94)$ & $0.96(0.74,1.36)$ \\
\hline
\end{tabular}

$P$, p-value obtained through a paired samples $t$-test between the sessions 1 and 2; ES, effect size; CV, coefficient of variation; ICC, intraclass correlation coefficient; SEM, standard error of measurement; 95\% CI, 95\% confidence interval. The letters represent the comparison between the procedures (TOV vs. FT) and jump types (Free-weight $v s$. Smith) separately for each loading condition. a, significantly more reliable than TOV-Free-weight; ${ }^{\mathrm{b}}$, significantly more reliable than TOV-Smith; ${ }^{\mathrm{c}}$, significantly more reliable than FT-Free-weight; ${ }^{\mathrm{d}}$, significantly more 
reliable than FT-Smith. Significant differences are determined as a CV ratio higher than 1.15 and a ICC below the lower limit of the $95 \%$ CI of other condition.

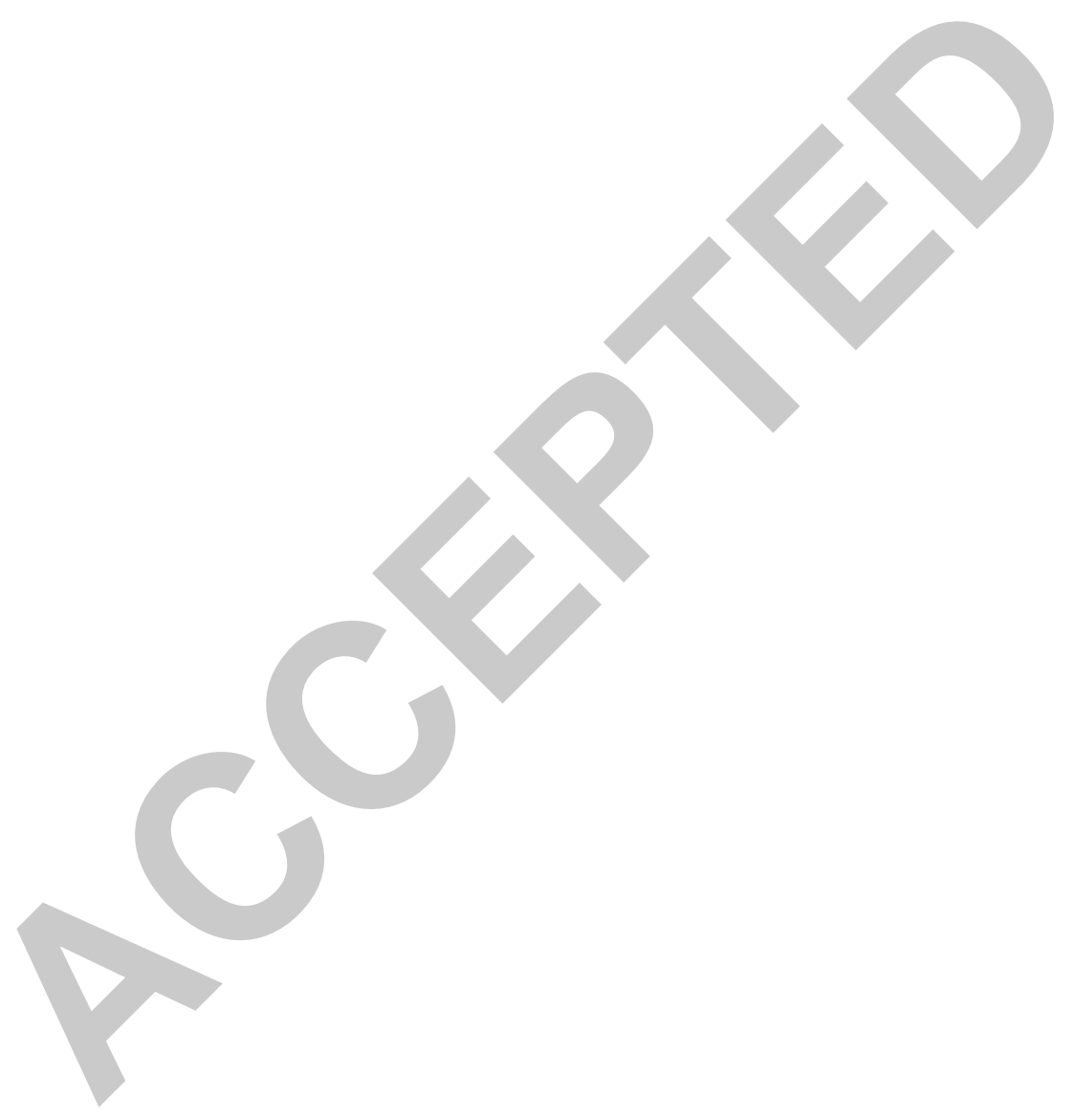




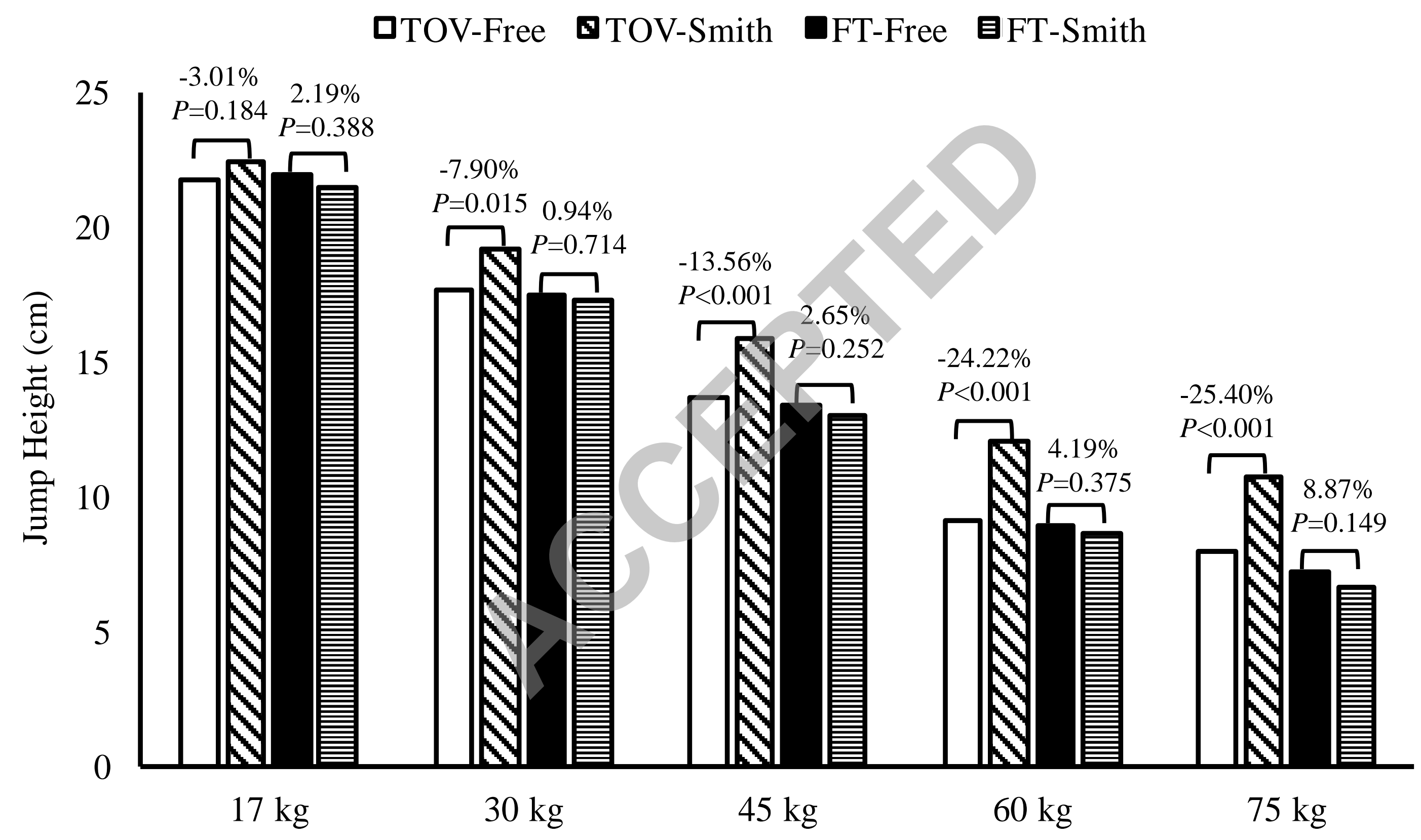




\section{FREE-WEIGHT}
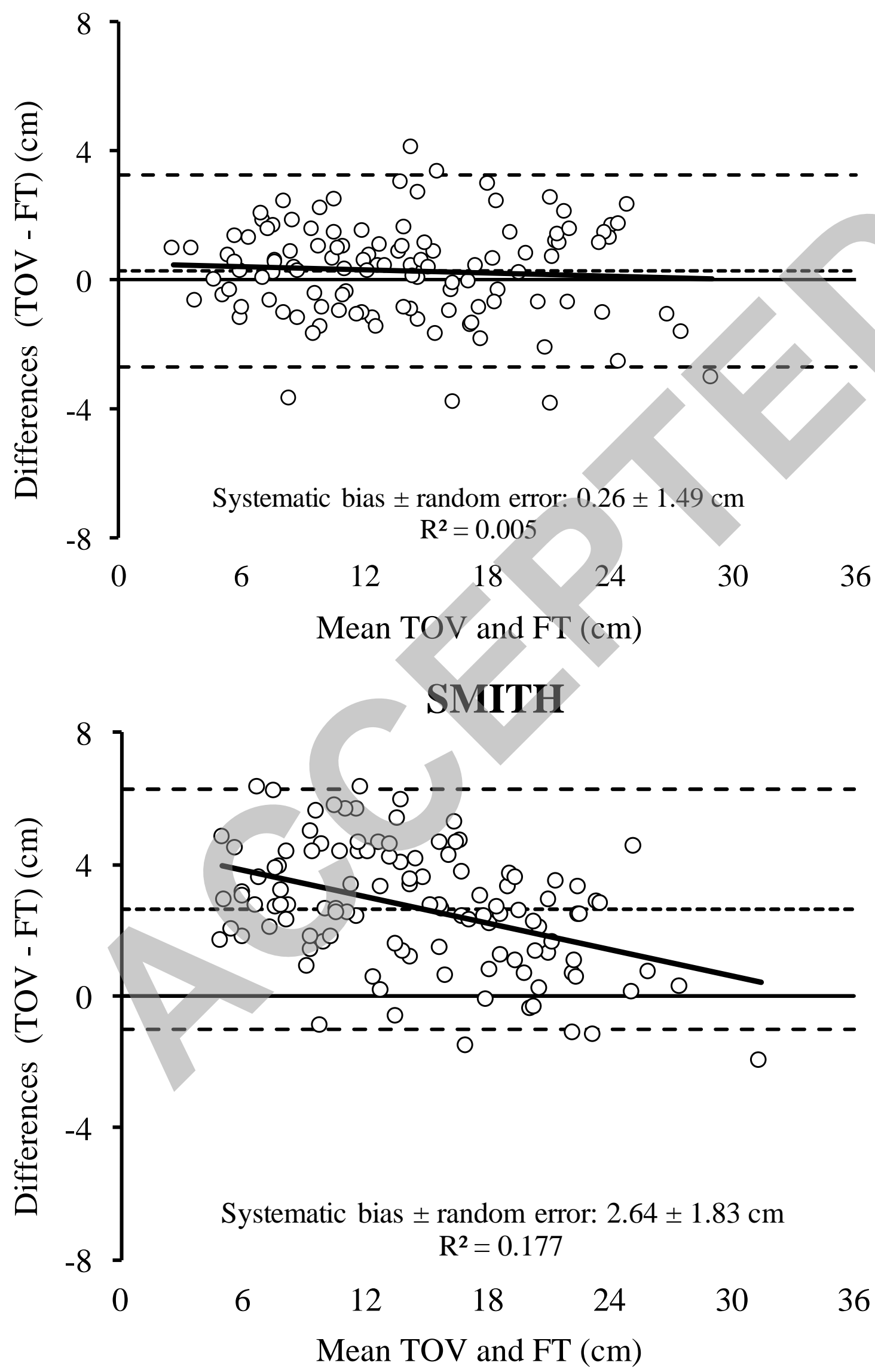